\title{
Microsystem Technologies: foreword to special issue on design, test, integration and packaging of MEMS/MOEMS, 2010
}

\author{
Bernard Courtois · Bernd Michel
}

Published online: 16 April 2011

(C) Springer-Verlag 2011

The symposium on design, test, integration and packaging of MEMS/MOEMS (DTIP) was held in Seville, Spain, 5-7 May 2010, as a follow up to previous issues held in 1999 and 2000 in Paris, France, in 2001, 2002, 2003 in Mandelieu-La Napoule, France, in 2004 and 2005 in Montreux, Switzerland, and in 2006, 2007 in Stresa, Italy, in 2008 in Nice, France and in 2009 in Rome, Italy. This series of symposia is a unique single-meeting event expressly planned to bring together participants interested in manufacturing microstructures and participants interested in design tools to facilitate the conception of these microstructures. The symposium is traditionally composed of two conferences running in parallel: one on CAD, design and test (CDT), and another one on microfabrication, integration and packaging (MIP). In addition, participants of both conferences can attend invited talks and special sessions.

This special issue is collecting reviewed and unabridged versions of papers presented at the symposium. The papers have been again refereed, along the usual refereeing process in force at Microsystem Technologies. We are proud to offer these papers to the readers of this journal now.
From 37 revised papers submitted to this special issue, 28 papers have been finally selected. They cover a broad range of topics. They appear in the Special Issue in the following order. A first large collection of ten papers on design, modeling and simulation of devices and components, five papers on embossing and mould, five papers on sensors and read-out circuitry, four papers on packaging and finally two papers on fabrication and two on measurement.

We hope that you enjoy these contributions as much as we did.<smiles>C#CCCCCC#C</smiles>

Bernard Courtois

DTIP Chair and

Guest Editor, Microsystem Technologies

B. Ma da

Bernd Michel

Head of Micro Materials Center, Editor-in-Chief, Microsystem Technologies

B. Courtois $(\varangle) \cdot$ B. Michel

Microsystem Technologies, Grenoble, France

e-mail:dtip@imag.fr 